\title{
Investigation of Particle Accumulation, Chemosensitivity and Thermosensitivity for Effective Solid Tumor Therapy Using Thermosensitive Liposomes and Hyperthermia
}

\author{
Wouter J.M. Lokerse1, Michiel Bolkestein¹, Timo L.M. ten Hagen¹, Marion de Jong², Alexander M.M. \\ Eggermont $^{3}$, Holger Grüll14, ${ }^{\bowtie}$, Gerben A. Koning ${ }^{1^{\dagger}}$ \# \\ 1. Laboratory Experimental Surgical Oncology, Section Surgical Oncology, Department of Surgery, Erasmus MC, Rotterdam, The Netherlands. \\ 2. Departments of Nuclear Medicine and Radiology, Erasmus MC, Rotterdam, the Netherlands. \\ 3. Gustave Roussy Cancer Campus Grand Paris, Villejuif Paris, France. \\ 4. Eindhoven University of Technology, Department of Biomedical NMR, Eindhoven, The Netherlands. \\ 5. Philips Research Eindhoven, Department of Oncology Solutions, Eindhoven, The Netherlands
}

† Deceased 29th of December 2015.

\# Dedicated to Gerben Koning, our friend, colleague and co-author, for his contribution to the field of hyperthermia and liposomal drug delivery. Sadly, much of his dreams remained unfinished.

$₫$ Corresponding author: Holger Grüll, Den Dolech 2, 5600 MB Eindhoven, Tel: +31 612932309 Email: h.gruell@tue.nl.

(0) Ivyspring International Publisher. Reproduction is permitted for personal, noncommercial use, provided that the article is in whole, unmodified, and properly cited. See http://ivyspring.com/terms for terms and conditions.

Received: 2016.01.13; Accepted: 2016.05.01; Published: 2016.06.24

\begin{abstract}
Doxorubicin (Dox) loaded thermosensitive liposomes (TSLs) have shown promising results for hyperthermia-induced local drug delivery to solid tumors. Typically, the tumor is heated to hyperthermic temperatures $\left(41-42^{\circ} \mathrm{C}\right)$, which induced intravascular drug release from TSLs within the tumor tissue leading to high local drug concentrations ( 1 -step delivery protocol). Next to providing a trigger for drug release, hyperthermia $(\mathrm{HT})$ has been shown to be cytotoxic to tumor tissue, to enhance chemosensitivity and to increase particle extravasation from the vasculature into the tumor interstitial space. The latter can be exploited for a 2-step delivery protocol, where HT is applied prior to i.v. TSL injection to enhance tumor uptake, and after 4 hours waiting time for a second time to induce drug release. In this study, we compare the 1- and 2-step delivery protocols and investigate which factors are of importance for a therapeutic response. In murine B16 melanoma and BFS-1 sarcoma cell lines, HT induced an enhanced Dox uptake in 2D and 3D models, resulting in enhanced chemosensitivity. In vivo, therapeutic efficacy studies were performed for both tumor models, showing a therapeutic response for only the $l$-step delivery protocol. SPECT/CT imaging allowed quantification of the liposomal accumulation in both tumor models at physiological temperatures and after a HT treatment. A simple two compartment model was used to derive respective rates for liposomal uptake, washout and retention, showing that the B16 model has a twofold higher liposomal uptake compared to the BFS-1 tumor. HT increases uptake and retention of liposomes in both tumors models by the same factor of 1.66 maintaining the absolute differences between the two models. Histology showed that HT induced apoptosis, blood vessel integrity and interstitial structures are important factors for TSL accumulation in the investigated tumor types. However, modeling data indicated that the intraliposomal Dox fraction did not reach therapeutic relevant concentrations in the tumor tissue in a 2-step delivery protocol due to the leaking of the drug from its liposomal carrier providing an explanation for the observed lack of efficacy.
\end{abstract}

Key words: Drug delivery, hyperthermia, thermosensitive liposome, intravascular drug release, particle accumulation. 


\section{Introduction}

Classical chemotherapy for treatment of solid tumors typically employs cytotoxic drugs with low molecular weight that have sizes below $1 \mathrm{~nm}$. The latter allows the drugs to efficiently extravasate upon injection from the vascular compartment into the tumor tissue in order to reach their targets. However, as extravasation is not restricted to the tumor tissue, toxicity imposed on healthy tissues is limiting the therapeutic window. One approach to limit off-target toxicity is the encapsulation of cytotoxic drugs into nanoparticles, such as liposomes with sizes in the range of 50-200 $\mathrm{nm}$, which reduces side effects observed for free drugs. In contrast to healthy tissues, tumors exhibit a poorly organized vascular system [1, 2] with endothelial gaps $[3,4]$ that allow extravasation and accumulation of nanoparticles up to several hundred nanometers [1, 5]. In addition, as tumors often lack a functional lymphatic system, which impedes efficient clearance of nanoparticles, substantial retention of long circulating nanoparticles is observed [6, 7]. This enhanced permeability and retention (EPR) effect was first described for macromolecules by Matsumura and Maeda [8] and is a prerequisite for liposomal drug targeting. Today, several lipomosal drug formulations are clinically approved, mostly due to their improved toxicity profile [7]. One example is Doxil®, a long circulation liposomal formulation of Doxorubicin (Dox) [9, 10]. While liposomal encapsulation reduces off-site toxicity, it unfortunately reduces bioavailabity of the parent drug. Drug release from the liposomal carrier is slow as it is based on passive diffusion of the drug across the liposomal lipid bilayer, which strongly reduces peak concentrations [11]. An alternative approach is heat-triggered drug delivery using a drug that is encapsulated in the aqueous core of a temperature sensitive liposome (TSL), as first proposed by Yatvin and Weinstein [12]. A TSL retains the drug at body temperature, but rapidly release their payload at mild hyperthermic temperatures $\left(40-43^{\circ} \mathrm{C}\right)$. Heating the targeted tissue to these temperatures, for example using radiofrequency or high intensity focused ultrasound, leads to rapid intravascular release with subsequent substantial drug deposition in the tumor, which is investigated in numerous preclinical [13-17], yet also clinical studies $[18,19]$.

Next to providing a trigger for drug release, hyperthermia (HT) exposure can induce multiple other changes on cellular as well as tissue level [20, 21]. HT can cause direct cytotoxicity in vitro [22] and in vivo, which depends on the absolute temperature and exposure time, but also on the type of cell or tissue [23, 24]. Secondly, HT can increase chemosensitivity [25, 26] due to a synergistic effect between HT- and drug-induced cytotoxicity or due to an increased drug uptake as HT enhances cell membrane permeability $[27,28]$. On tissue level, preclinical studies have shown that HT increased liposomal uptake in tumors [29-33]. However, clinical trials using Doxil® in combination with HT showed variable therapeutic outcomes, highlighting the clinical need for liposomal formulations that could more effectively release the drug $[34,35]$. The latter inspired the design a 2-step drug delivery scheme, where first HT is applied to enhance the EPR effect followed by injection of TSLs. After accumulation of TSLs in the tumor, drug release is triggered with a second application of HT to ensure bioavailability of the drug.

In a previous study, $\mathrm{Li}$ et al. performed a comparative study with Dox loaded TSL using the aforementioned 2-step drug delivery scheme versus a 1-step intravascular HT-drug delivery scheme in a murine BLM melanoma model [36]. The conclusion of that study was that a 1-step treatment was more efficacious in treating a solid tumor than the 2-step approach. Here we provide a follow-up study, investigating 1-step and 2-step HT TSL based treatments in terms of in vitro cytotoxicity, drug uptake by cells, therapeutic efficacy and quantitative TSL uptake by B16 melanoma and BFS-1 sarcoma tumors. Furthermore, extensive ex vivo investigation provide data giving more insights into microenvironmental factors that could play a role in TSL accumulation for B16 and BFS-1 tumors and the influence of HT on these factors.

\section{Materials \& Methods}

\section{Materials}

1,2-distearoyl-sn-glycero-3-phosphocholine (DSPC), 1,2-dipalmitoyl-sn-glycero-3-phosphocholine (DPPC) and 1,2-distearoyl-sn-glycero-3-phosphoethanolamine-N-(amino(polyethylene glycol)-2000) (DSPE-PEG 2000 ) were purchased from Lipoid (Ludwigshafen, Germany). DSPE-diethylenetriaminepentaacetic acid (DTPA) was obtained from Avanti Polar Lipids Inc. (Alabaster, AL). Doxorubicin-hydrochloride solution $(2 \mathrm{mg} / \mathrm{ml})$ was ordered from Accord Healthcare. 4-(2-hydroxyethyl)1-piperazineethanesulfonic acid (HEPES), $\left(\mathrm{NH}_{4}\right)_{2} \mathrm{SO}_{4}$, DMEM culture medium, fetal bovine serum (FBS), sulforhodamine B (SRB), poly(2-hydroxyethylmethacrylate; HEMA), 2-Amino-2-hydroxymethyl- 
propane-1,3-diol (Tris), NaCl, glycerol, Mayer's hematoxylin, eosin Y, Martius yellow, crystal scarlet and methyl blue were from Sigma Aldrich (St. Louis, MO). Nonyl phenoxypolyethoxylethanol (NP40) was purchased from ICN Biomedicals (Irvine, CA). Penicillin-streptomycin (Pen-Strep) solution was from Lonza (Breda, Netherlands). PD-10 desalting columns were bought from GE Healthcare Life Sciences (Buckinghamshire, UK). Entallan and rabbit-anti mouse Collagen IV antibody were from EMD Millipore (Billerica, MA). CD31 antibody (rat anti-mouse) was bought from Abcam (Cambridge, UK) and AlexaFluor 594 (goat anti-rat) and AlexaFluor 488 (goat anti-rabbit) from Invitrogen (Carlsbad, CA). Matrigel was acquired from BD (San Jose, CA). Cryo compound was from Klinipath (Duiven, Netherlands). Fluoromount-G was provided by Southern Biotech (Birmingham, AL). Cell death detection kit was obtained from Roche (Woerden, Netherlands). Weigert's hematoxylin was purchased from Boom Chemicals (Meppel, Netherlands).

\section{Liposome preparation}

DPPC:DSPC:DSPE-PEG 2000 at a molar ratio of 70:25:5 were dissolved in 9:1 (vol:vol) chloroform/methanol. Solvent was evaporated using a rotary evaporator and the resulting lipid film was flushed under a stream of nitrogen. The lipid film was hydrated with a $250 \mathrm{mM}$ solution of $\left(\mathrm{NH}_{4}\right)_{2} \mathrm{SO}_{4}$ buffer pH 5.5 and extruded five times through $200 \mathrm{~nm}, 100$ $\mathrm{nm}, 80 \mathrm{~nm}$ and $50 \mathrm{~nm}$ polycarbonate membrane filters. A pH gradient was established using a PD-10 column and eluting the liposomes with a $\mathrm{pH} 7.4$ HEPES buffered saline (10 mM HEPES, $135 \mathrm{mM}$ $\mathrm{NaCl}$ ). Phosphate concentration was determined by ammonium molybdate assay [37]. Dox was loaded into the liposomes by mixing Dox and lipid at a ratio of $0.15: 1$ (mol:mol) and incubating it for $1 \mathrm{~h}$ at $39^{\circ} \mathrm{C}$ in a thermoshaker. Liposomes were concentrated by ultracentrifugation $\left(193000 \mathrm{~g}, 2 \mathrm{~h}, 4^{\circ} \mathrm{C}\right)$ and resuspended in $10 \mathrm{mM}$ HEPES buffered saline $\mathrm{pH} 7.4$ yielding the final formulation of Dox-loaded TSLs
(TSLDox).

\section{Radiolabeled liposome preparation}

For radiolabeled TSLs (111In-TSL), $0.1 \mathrm{~mol} \%$ DSPE-DTPA was added to the formulation described above and produced in a similar fashion as the regular TSLs, with the exception that the liposomes were not loaded with Dox. $1 \mu \mathrm{mol}$ TSLs was incubated with 30 $\mathrm{MBq}{ }^{111} \mathrm{In}$ for $15 \mathrm{~min}$ at room temperature after the $\mathrm{pH}$ was set at 5.0 with $2.5 \mathrm{M}$ sodium acetate. After incubation, labeling efficiency was determined by ITLC-SG (Varian Inc.) and the final volume was adjusted to $200 \mu \mathrm{L}$ with HEPES buffered saline (10 mM HEPES, $135 \mathrm{mM} \mathrm{NaCl}$, pH 7.4).

\section{Cellular toxicity assay}

B16 or BFS-1 cells were seeded in 96-well plates and allowed to grow till 50\% confluency in DMEM medium enriched with 10\% FBS and 1\% Pen-Strep. The medium was removed and fresh medium with a desired amount of free Dox or TSL Dox $_{\text {was }}$ brought onto the cells and incubated according to Scheme 1. NT: incubation with Dox for $1 \mathrm{~h}$ at $37^{\circ} \mathrm{C} ; \mathrm{HT}_{42}$ : incubation with Dox for $1 \mathrm{~h}$ at $42^{\circ} \mathrm{C}$; $\mathrm{HT}_{41}-\mathrm{NT}$ : Preheating cells $1 \mathrm{~h}$ at $41^{\circ} \mathrm{C}, 4 \mathrm{~h}$ recovery at $37^{\circ} \mathrm{C}$ and a $1 \mathrm{~h}$ incubation with Dox at $37^{\circ} \mathrm{C} ; \underline{H T}_{41}-\mathrm{HT}_{42}$ : Preheating cells for $1 \mathrm{~h}$ at $41^{\circ} \mathrm{C}, 4 \mathrm{~h}$ recovery at $37^{\circ} \mathrm{C}$ and a $1 \mathrm{~h}$ incubation Dox at $42^{\circ} \mathrm{C}$. For a TSL treatments on cells, $10 \mu \mathrm{M}$ Dox was used. To apply HT, plates were put into a water bath set at the required temperature. After incubation, the Dox containing medium was removed and cells were given fresh medium for $24 \mathrm{~h}$ or $48 \mathrm{~h}$ incubation at $37^{\circ} \mathrm{C}$. Cells were fixed using $10 \%(\mathrm{w}: \mathrm{v})$ trichloroacetic acid (TCA). After fixation, the plates were washed with water and $0.5 \%$ SRB solution was added to stain the fixed cells for $20 \mathrm{~min}$. When staining was completed, cells were washed with $1 \%$ acetic acid and left to dry. $10 \mathrm{mM}$ Tris was added to resuspend the SRB and absorbance was measured at $590 \mathrm{~nm}$ by spectrophotometry (Wallac Victor 2 Counter).

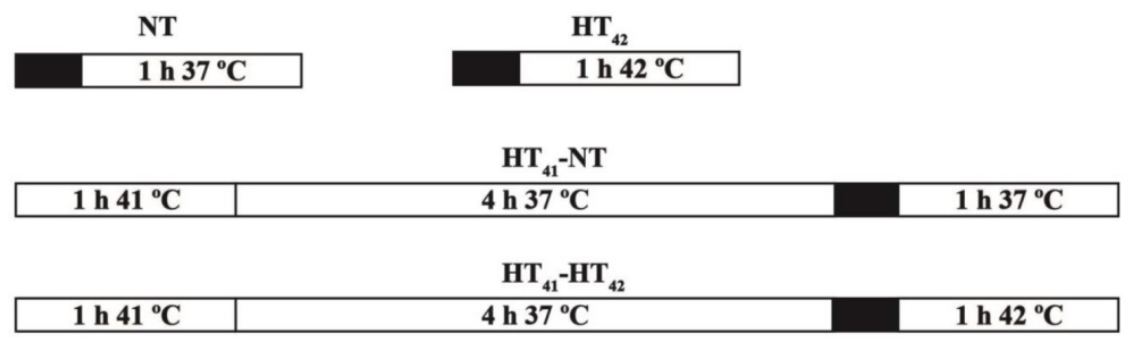

Dox added

Scheme 1. Overview of different in vitro Dox uptake treatments. Dox exposure took place at $37^{\circ} \mathrm{C}(\mathrm{NT})$ or $42^{\circ} \mathrm{C}(\mathrm{HT} 42)$. In two additional groups, cells were preheated for $1 \mathrm{~h}$ at $41^{\circ} \mathrm{C}\left(\mathrm{HT}_{41}\right)$ with a $4 \mathrm{~h}$ recovery at $37^{\circ} \mathrm{C}$ before Dox uptake under $\mathrm{NT}$ or $\mathrm{HT}_{42}$ conditions (HT4I-NT and $\mathrm{HT}_{4 \mathrm{I}}-\mathrm{HT}_{42}$, respectively) 


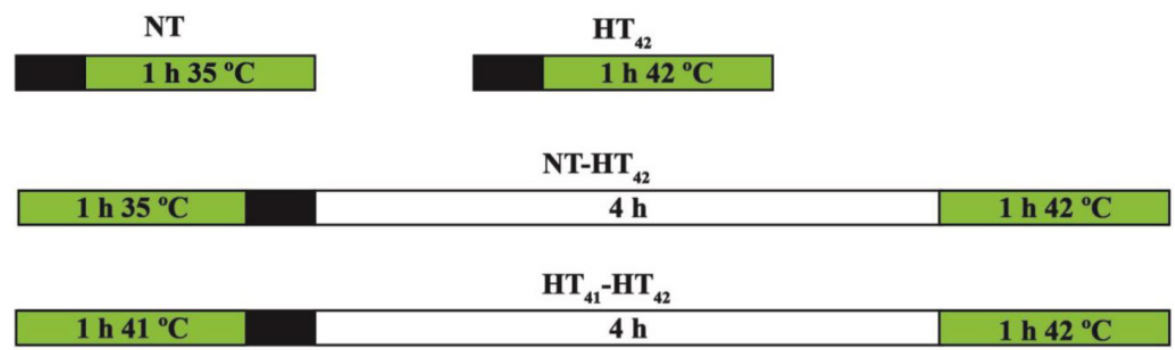

\begin{tabular}{l}
\hline TSL $_{\text {Dox }}$ or PBS injection \\
$\square$ Anesthesia
\end{tabular}

Scheme 2. Overview of 1-step and 2-step treatments in vivo. For 1-step, i.v. TSLDox administration was conducted at body temperature (NT) or when the tumor was brought to $42^{\circ} \mathrm{C}\left(\mathrm{HT}_{42}\right)$. 2-step treatments were composed of keeping the mouse under anesthesia at body temperature for $1 \mathrm{~h}\left(\mathrm{NT}-\mathrm{HT}_{42}\right)$ or preheating the tumor at $41{ }^{\circ} \mathrm{C}$ for $1 \mathrm{~h}\left(\mathrm{HT}_{41}-\mathrm{HT}_{42}\right)$, prior to TSLDox injection, $4 \mathrm{~h}$ rest and a second tumor heating at $42^{\circ} \mathrm{C}$.

\section{Cellular Doxorubicin uptake in 2D and 3D models}

B16 or BFS-1 cells were seeded into $75 \mathrm{~cm}^{2}$ flasks and grown under similar conditions as mentioned above until $80 \%$ confluency was reached. The cells were subjected to $40 \mu \mathrm{M}$ Dox under four different treatment conditions as stated in Scheme 1. Exposing cells to elevated temperatures was done by submerging the $75 \mathrm{~cm}^{2}$ culture flask into a water bath. After incubation, the cells were washed with ice cold PBS, scraped from the flask and centrifuged at $200 \mathrm{~g}$ at $4^{\circ} \mathrm{C}$. The pellets were resuspended in $150 \mu \mathrm{L}$ lysis buffer $(20 \mathrm{mM}$ Tris, $150 \mathrm{mM} \mathrm{NaCl}, 0.2 \%$ NP40, 10\% glycerol, $\mathrm{pH}$ 7.4), followed by 30 min incubation on ice and centrifugation at $14000 \mathrm{~g}$. The pellets were resuspended and homogenized in $500 \mu \mathrm{L}$ PBS by brief probe sonication and Dox concentration was measured by fluorometry at $485 \mathrm{~nm}$ excitation and $580 \mathrm{~nm}$ emission (Wallac Victor 2 Counter). Tumor spheroids were made according to a previously described method [38]. In short, conical shaped 96-well plates were coated with poly-HEMA and $1 \mathrm{x}$ $10^{5}$ cells which were centrifuged at $1000 \times g$ for $10 \mathrm{~min}$ in the presence of $2.5 \%$ Matrigel and incubated overnight at $37^{\circ} \mathrm{C}$. After incubation, spheroids were handpicked and exposed to identical treatments as in the 2D model in a thermoshaker (no shaking). After incubation, the spheroids were washed in PBS, embedded into Fluoromount-G and imaged by confocal microscopy (Zeiss LSM 510 Meta; Oberkochen, Germany). A $5 \mu \mathrm{m}$ Z-stack was made over the surface of the spheroid to determine total Dox fluorescence. For each optical slice, the amount of saturated Dox fluorescence pixels were counted. The sum of saturated pixels of all tumor slices was used as an indicator for Dox uptake. For cryo-sectioning, spheroids were embedded into Cryo Compound and snap frozen in liquid nitrogen. $10 \mu \mathrm{m}$ slices were made using a Cryostat (Leica CM1850 UV; Wetzlar,
Germany), and afterwards embedded into Fluoromount-G and imaged using fluorescence microscopy (Zeiss Axiovert 100M; Hamamatsu Photonics C4742-98 camera controller).

\section{$B 16$ and BFS-1 tumor generation}

Murine B16 melanoma or BFS-1 sarcoma cells (1 $\left.x 10^{6}\right)$ were subcutaneously injected into the flank of C57BL6 mice (Harlan) to grow bulk tumors. After reaching volumes of approx. $700 \mathrm{~mm}^{3}$, animals were sacrificed and tumor pieces were transplanted to the animals of the therapeutic studies. All animal experiments were approved by the Erasmus MC animal research committee, Rotterdam, The Netherlands.

\section{Therapeutic efficacy studies in a B 16 and BFS-1 model}

$1 \mathrm{~mm}^{3}$ B16 or BFS-1 tumor pieces were transplanted subcutaneously onto the hind limb of C57BL6 mice and allowed to grow to $200 \mathrm{~mm}^{3}$ after which treatments were initiated as shown in Scheme 2. NT: 1-step with $100 \mu \mathrm{L}$ i.v. PBS injection and $1 \mathrm{~h}$ anesthesia at body temperature; $\mathrm{HT}_{42}$ : 1-step with 100 $\mu \mathrm{L}$ i.v. PBS injection and $1 \mathrm{~h}$ anesthesia with heated tumor at $42{ }^{\circ} \mathrm{C}$; TSLDox NT: 1-step with $100 \mu \mathrm{L} 5$ $\mathrm{mg} / \mathrm{kg}$ TSLDox i.v. injection and $1 \mathrm{~h}$ anesthesia at body temperature; TSLDox HT $_{42}: 1$-step with $100 \mu \mathrm{L} 5 \mathrm{mg} / \mathrm{kg}$ TSL Dox i.v. injection and $1 \mathrm{~h}$ anesthesia with heated tumor at $42{ }^{\circ} \mathrm{C} ; \mathrm{HT}_{41}-\mathrm{HT}_{42}$ : 2-step with $1 \mathrm{~h}$ preheating tumor at $41{ }^{\circ} \mathrm{C}$ under anesthesia, $100 \mu \mathrm{L}$ i.v. PBS injection, $4 \mathrm{~h}$ waiting period and $1 \mathrm{~h}$ anesthesia with heated tumor at $42{ }^{\circ} \mathrm{C}$; TSLDox NT-HT ${ }_{42}$ : 2-step with 1 $\mathrm{h}$ anesthesia at body temperature, $100 \mu \mathrm{L} 5 \mathrm{mg} / \mathrm{kg}$ TSL $_{\text {Dox }}$ i.v. injection, $4 \mathrm{~h}$ waiting period and $1 \mathrm{~h}$ anesthesia with heated tumor at $42{ }^{\circ} \mathrm{C}$; TSLDox $\underline{\mathrm{HT}}_{41}-\mathrm{HT}_{42}:$ 2-step with $1 \mathrm{~h}$ preheating tumor at $41^{\circ} \mathrm{C}$ under anesthesia, $100 \mu \mathrm{L} 5 \mathrm{mg} / \mathrm{kg}$ TSL $_{\text {Dox }}$ i.v. injection, $4 \mathrm{~h}$ waiting period and $1 \mathrm{~h}$ anesthesia with heated tumor at $42{ }^{\circ} \mathrm{C}$. In the 1-step treatment 
protocol, the tumor was submerged into a $42.5^{\circ} \mathrm{C}$ water bath for heating to $42^{\circ} \mathrm{C}$ for $10 \mathrm{~min}$, followed by an i.v. injection of TSL ( $5 \mathrm{mg} / \mathrm{kg}$ Dox) and further heating for another hour. The 2-step treatment procedure included heating of the tumor to $41{ }^{\circ} \mathrm{C}$ for one hour and an i.v. injection of TSL ( $5 \mathrm{mg} / \mathrm{kg}$ Dox) 10 min after heating. Afterwards, the animal was allowed to rest for $4 \mathrm{~h}$, followed by a second HT treatment for $1 \mathrm{~h}$ at $42{ }^{\circ} \mathrm{C}$. In control groups normothermic (NT; $\left.35{ }^{\circ} \mathrm{C}\right)$ conditions were used, where the animal was put under anesthesia for $1 \mathrm{~h}$ and kept at $35{ }^{\circ} \mathrm{C}$ on a $37^{\circ} \mathrm{C}$ heating plate while covering the animal with tin foil. During both HT and NT experiments, the tumor bearing limb, with exception of the tumor itself, was coated in vaseline to prevent possible skin burns. Body temperatures of the mice were measured using a rectal probe.

\section{SPECT/CT imaging of TSL accumulation in a $B 16$ and BFS-1 model}

$1 \times 10^{6}$ cells were subcutaneously injected on the hind limb of C57BL6 mice and tumors were allowed to grow to volumes of $200 \mathrm{~mm}^{3}$. Tumors were either heated for one hour at $41^{\circ} \mathrm{C}$ prior to injection or kept at $35{ }^{\circ} \mathrm{C}$ in a similar fashion as for the therapeutic study. ${ }^{111} \mathrm{In}$-TSL were i.v. injected $(200 \mu \mathrm{L}$ per mouse with an average activity of $33 \pm 2 \mathrm{MBq}{ }^{111} \mathrm{In}$ ) and scans were made $4 \mathrm{~h}, 8 \mathrm{~h}, 24 \mathrm{~h}$ and $48 \mathrm{~h}$ after injection. Scans were acquired using the nanoSPECT/CT (Mediso Medical Imaging Systems) with the following settings for the SPECT scans: 20 projections, 60 seconds/ projection, and a quality factor of 0.8 . APT1 apertures were used with $1.4 \mathrm{~mm}$ diameter pinholes (FOV $24+$ $16 \mathrm{~mm}$ ). CT scans were acquired with 240 projections, $45 \mathrm{kVp}$ tube voltage and $500 \mathrm{~ms}$ exposure. Data analysis was performed using InVivoScope/ VivoQuant software (inviCRO, Boston, MA), where three-dimensional regions of interest were drawn over the tumor to calculate uptake of ${ }^{111}$ In-TSL at the selected time points. After the last scan, the animals were sacrificed and tumors and organs were harvested, weighed and radioactivity was determined using a $\gamma$-counter to calculate percentage injected dose per gram $(\% \mathrm{ID} / \mathrm{g})$. All data were corrected for radioactive decay.

\section{Pharmacokinetic modelling:}

The blood kinetics and pharmacokinetic parameters of the TSL $\mathrm{Tox}_{\text {formulation were }}$ determined in an earlier study (Figure S1) [39]. Results from that study showed that the blood half-life of liposomal carrier $C_{\text {lip }}(t)$ can be described with a mono-exponential function:

$$
C_{l i p}(t)=C_{l p p}(t=0) \cdot \operatorname{Exp}\left(-\ln 2 / t_{1 / 2, T S} \cdot t\right) \quad(\mathrm{Eq} .1)
$$

with $C_{\text {lip }}(0)=100 \% \mathrm{ID}$ at time point of injection and $t_{1 / 2, \text { TSL }}=5.6 \pm 0.4 \mathrm{~h}$ being the circulation half-life of the liposomes. Upon injection, a fraction of Dox is instantaneous released (Burst $=8 \pm 3 \%$ ) followed by a slow leakage of Dox from the liposomal carrier with a half-life of $t_{1 / 2, \text { leak }}=2.7 \pm 0.3 \mathrm{~h}$. The concentration of intraliposomal dox $C_{D o x, T S L}(t)$ can be described with the following equation:

$$
C_{D o x, T S \mathrm{~L}}(t)=(1-B u r s t / 100) \cdot \operatorname{Exp}\left(-\ln 2 / t_{1 / 2, \text { bank }} \cdot t\right) \cdot C_{\text {lep }}(t)
$$

The concentration of (radiolabeled) liposomes in the tumor, $C_{T S L, t u m o r}(t)$, can be described with a simple two compartment model:

$$
\frac{\partial C_{\text {TSL,tumor }}(t)}{d t}=k_{\text {in }} \cdot C_{\text {lip }}(t)-k_{\text {out }} \cdot C_{\text {TSL,tumor }}(t)+k_{\text {ret }}
$$

(Eq. 3)

where $k_{\text {in }}, k_{\text {out }}$ and $k_{\text {ret }}$ describe the rates of uptake, washout and retention of TSL in the tumor compartment.

Concentration of intraliposomal Dox within the tumor is subsequently numerically calculated assuming the same burst and leakage of Dox from the liposomal carrier as found for TSLDox in the blood compartment.

Numerical integration of Eq. 3 and fitting of the SPECT data was performed using Mathematica ${ }^{\circledR}$ (version 10.2, Wolfram Research).

\section{Histology}

After the SPECT/CT experiments, the excised tumors were snap frozen in liquid nitrogen. $5 \mu \mathrm{m}$ slices were cut and tumors were stained for vessels with an anti-CD31 antibody and AlexaFluor 594 or collagen with anti-collagen IV antibody and AlexaFluor 488. The TUNEL staining was performed with a cell death detection kit. The CD31 and TUNEL stains were quantified using ImageJ (version 1.48) software and by setting a manual threshold. A second set of frozen slices was stained with Maier's hematoxylin and Eosin (H\&E) or by Weigert's hematoxylin, Martius yellow, crystal scarlet and methyl blue (MSB), followed by mounting in Entallan. The slices were imaged for fluorescence by confocal microscopy (CD31, collagen IV \& TUNEL) or bright field microscopy (Leica DM 4000B) for H\&E and MSB stained sections.

\section{Statistics}

All statistical tests were carried out using Graphpad Prism 5 software. All figures were subjected to unpaired two tailed t-test or one-way 
ANOVA Bonferroni test with significant difference at $\mathrm{p}<0.05$.

\section{Results}

\section{Preparation of TSLDox}

Loading of TSL with the formulation DPPC:DSPC:DSPE-PEG 2000 at a molar ratio of 70:25:5 with Dox was achieved with $100 \%$ efficacy. Dynamic light scattering of the resulting TSL ${ }_{\text {Dox }}$ indicated an average hydrodynamic diameter of $83 \pm 3 \mathrm{~nm}$ and a zeta-potential of $-7.9 \pm 0.9 \mathrm{mV}$. Stability at $37^{\circ} \mathrm{C}$ and release kinetics at $42{ }^{\circ} \mathrm{C}$ were tested in culture medium (10\% FBS and 1\% Pen-Strep) and were found to be similar to results obtained with $100 \%$ FBS as described in our previous work (Figure S2) [39].

\section{Cytotoxic assays on B 16 melanoma and BFS-1 sarcoma cells}

In an in vitro study, murine B16 melanoma and BFS-1 sarcoma cells were exposed to various Dox concentrations for $1 \mathrm{~h}$ under the conditions depicted in Scheme 1. Both cell lines showed an increased sensitivity to Dox when the drug exposure was performed at hyperthermic temperatures (Figure 1). For B16 (Figure 1A, B) and BFS-1 (Figure 1C, D), the Dox sensitivity increased 8-fold. Additional pre-heating $\left(\mathrm{HT}_{41}-\mathrm{HT}_{42}\right)$ did not result in a further increase in Dox sensitivity for B16. However, the 18-fold increase for BFS-1 was significantly higher than the single HT treatment. In this case direct HT-induced cytotoxicity could have played a predominant role (Figure S3). B16 and BFS-1 cells were furthermore tested for survival after incubation with TSL (empty), $10 \mu \mathrm{M}$ TSLDox or $10 \mu \mathrm{M}$ free Dox under normothermic $\left(\mathrm{NT} ; 37^{\circ} \mathrm{C}\right)$ and $\mathrm{HT}_{42}$ conditions for $1 \mathrm{~h}$. After the treatment, the cells were kept in culture medium for $24 \mathrm{~h}$ or $48 \mathrm{~h}$. At $37^{\circ} \mathrm{C}$, TSLDox induced little toxicity to the cells, while at $42{ }^{\circ} \mathrm{C}$ the release of Dox was sufficient to cause high cell death (Figure 2). The TSL by itself had no inhibitory effect on cell growth, while HT did show some direct cytotoxicity, which was only significant for B16 $24 \mathrm{~h}$ after incubation with $72 \pm 11 \%$ viable cells compared to the NT group (Figure 2A). The addition of $10 \mu \mathrm{M}$ $\mathrm{TSL}_{\text {Dox }}$ to a $1 \mathrm{~h}$ incubation with $\mathrm{HT}_{42}$ resulted in an immediate cytotoxic effect $24 \mathrm{~h}$ after the incubation (Figure 2A) with $25 \pm 6 \%$ for B16 and $57 \pm 7 \%$ cell survival for BFS-1. This cytotoxic effect became even more apparent $48 \mathrm{~h}$ after incubation, showing an almost complete cell death for both cell types (Figure 2B). The $\mathrm{TSL}_{\mathrm{Dox}} \mathrm{HT}_{42}$ group showed similar results as where $10 \mu \mathrm{M}$ free Dox was used (Dox $\mathrm{HT}_{42}$ ), suggesting a total Dox release from TSL $\mathrm{TLx}_{\text {in }}$ in these experimental conditions. A cytotoxicity assay using a 2-step heating protocol was not performed, as the main cytotoxic effect was caused by the increased uptake of free or released Dox during $\mathrm{HT}_{42}$.

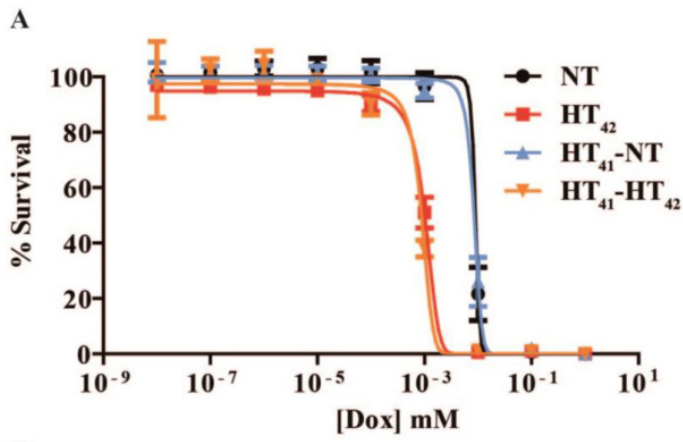

B

C

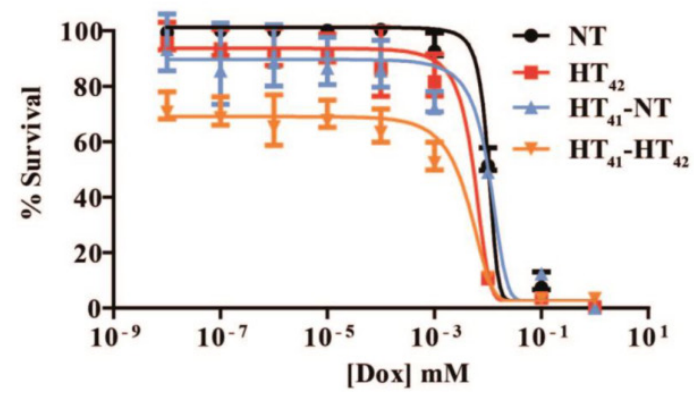

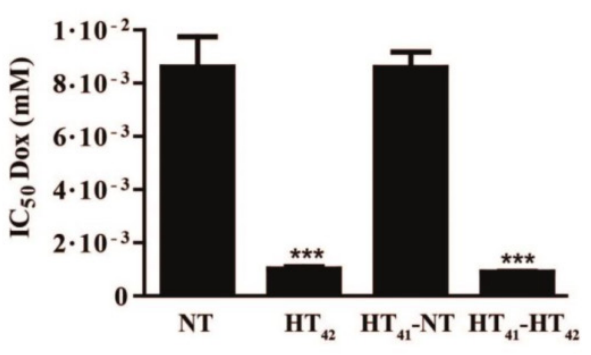

D

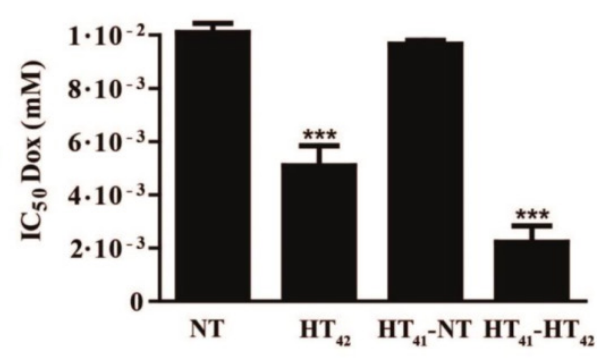

Figure 1. Dox cytotoxicity assay and IC 50 values for BI6 (A, B) and BFS-1 cells (C, D) 48 h after treatment by different hyperthermia protocols. $n=3$ for each data set. Curves were fit by non-linear regression and statistical analysis by one-way ANOVA Bonferroni test. The significance scores of all treatments versus NT groups are indicated with asterisks. $*=p<0.05, * *=p<0.01, * * *=p<0.005$ 

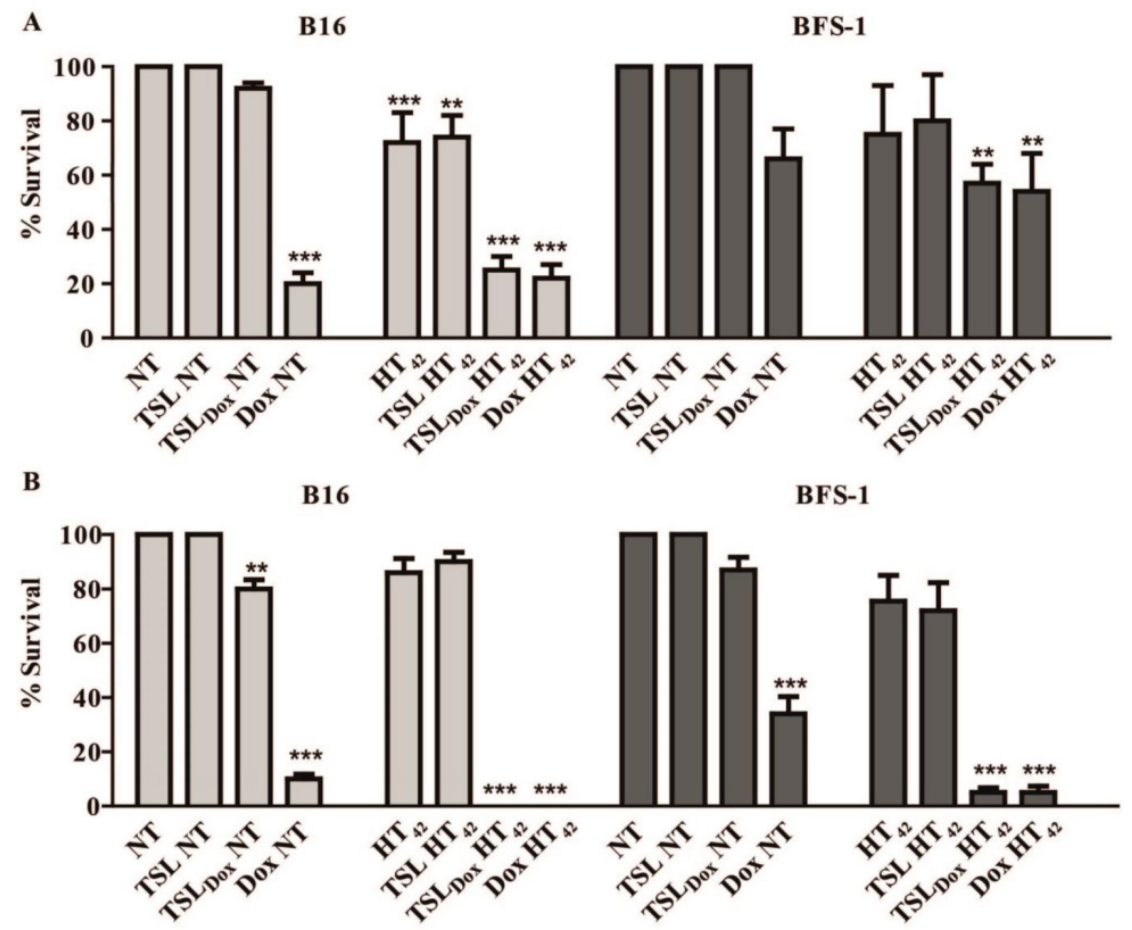

Figure 2. Cytotoxicity assay on B16 and BFS-1 cells $24 \mathrm{~h}(\mathrm{~A})$ and $48 \mathrm{~h}$ (B) after a $1 \mathrm{~h}$ incubation with $10 \mu \mathrm{M}$ TSLDox or free Dox under NT $\left(37^{\circ} \mathrm{C}\right)$ or $\mathrm{HT} 42\left(42^{\circ} \mathrm{C}\right)$ conditions. $n=3$ for each data set. Statistical analysis was carried out using one way ANOVA Bonferroni test comparing the treatment groups with the NT group separately at $24 \mathrm{~h}$ and $48 \mathrm{~h}$. The significance scores of all treatments versus NT groups are indicated with asterisks. $*=p<0.05, * *=p<0.01, * * *=p<0.005$.

\section{In vitro Doxorubicin uptake in 2D and 3D models}

Next, the effect of HT on Dox uptake was studied in B16 and BFS-1 cells. Both cell lines exhibited a linear uptake of Dox over time at body temperature (Figure 3A,B). Incubation of both cell lines with Dox at $\mathrm{HT}_{42}$ significantly increased Dox uptake 9-fold for B16 (Figure 3A) and 6-fold for BFS-1 cells (Figure 3B). Groups were added where the cells were preheated at $41^{\circ} \mathrm{C}$ for $1 \mathrm{~h}$ followed by $4 \mathrm{~h}$ at 37 ${ }^{\circ} \mathrm{C}$ to mimic a 2-step approach therapy. Preheating of the cells before incubation with Dox at NT $\left(\mathrm{HT}_{41}-\mathrm{NT}\right)$ or $\mathrm{HT}_{42}\left(\mathrm{HT}_{41}-\mathrm{HT}_{42}\right)$ conditions did not result in a significant difference compared to Dox uptake without preheating. Next, we used multicellular spheroids of BFS-1 cells to determine the Dox uptake as well as spatial distribution under the different temperature protocols in a 3D model. After performing similar incubation protocols as described before, the BFS-1 spheroids showed a similar pattern in Dox uptake than BFS-1 cells in the 2D standard culture conditions (Figure 3C, Video S1). When the Dox fluorescence intensity was quantified (Figure 3D), $\mathrm{HT}_{42}$ and $\mathrm{HT}_{41}-\mathrm{HT}_{42}$ presented significantly more Dox positive areas than NT spheroids with a 6-fold and 10-fold increase in the summation of saturated Dox fluorescence pixels, respectively. $\mathrm{HT}_{41}-\mathrm{NT}$ treatment did not result in a significantly enhanced uptake. Dox did not penetrate farther than the first few cell layers into the spheroid, despite the heating protocol used (Figure 3E). B16 cells did not form spheroids and could therefore not be studied in the 3D Dox uptake model.

\section{1-step \& 2-step therapeutic study}

A therapeutic study with B16 (Figure 4A, B) and BFS-1 (Figure 4C, D) tumors were subjected to 1-step or 2-step therapies (Scheme 2). We chose $41{ }^{\circ} \mathrm{C}$ as preheating temperature since it has been shown that an intratumoral increase of TSL Dox $_{\text {accumulation can }}$ be established [31] without risking significant vascular damage [40]. In both B16 and BFS-1 tumors, TSLDox with $\mathrm{HT}_{42}$ significantly outperformed all other treatments with an average improvement of survival of $7.1 \pm 1.4$ days for B16 and $14.6 \pm 2.8$ days for BFS-1 when compared to the NT group. The body temperature differed significantly between NT and $\mathrm{HT}_{42}$ treated mice (Figure S4). Nevertheless, it remained at a physiological level with $35.0 \pm 0.4{ }^{\circ} \mathrm{C}$ and $36.9 \pm 1.1^{\circ} \mathrm{C}$, respectively.

\section{Quantitative SPECT/CT imaging of TSL accumulation in solid tumors}

A SPECT/CT study with ${ }^{111}$ In-TSL (labeling efficiency $>99 \%$ ) was carried out to visualize the particle uptake in B16 and BFS-1 tumor bearing mice, comparing NT conditions versus tumor preheating for $1 \mathrm{~h}$ at $41^{\circ} \mathrm{C}$ prior to injection $\left(\mathrm{HT}_{41}\right)$. SPECT imaging over time showed that the majority of the 
injected ${ }^{111}$ In-TSL were cleared by liver and spleen (Figure 5A, B) with tumor uptake over time. For all tumors, a maximum uptake was observed approx. $4 \mathrm{~h}$ post injection followed by a slight reduction over time leveling off at $48 \mathrm{~h}$ post injection. Under NT conditions, plateau values of $3.2 \pm 0.5$ and $1 \pm 0.3$ $\% \mathrm{ID} / \mathrm{cc}$ were reached for B16 and BFS1 tumors respectively. Applying $\mathrm{HT}_{41}$ before injection increased uptake in both tumors, leading to higher maximum as well as plateau concentrations (B16: $6.2 \pm 1.5 \% \mathrm{ID} / \mathrm{cc}$, BFS1: $3.3 \pm 2.8 \% \mathrm{ID} / \mathrm{cc}$ at $48 \mathrm{~h}$ p.i.) (Figure $5 \mathrm{~A}-\mathrm{D}$ ). Biodistribution studies at $\mathrm{t}=48 \mathrm{~h}$ p.i. were consistent with data derived from SPECT showing an uptake of ${ }^{111} \mathrm{In}$-TSL in B16 tumors $2.8 \pm 0.5 \% \mathrm{ID} / \mathrm{g}$ compared to a considerable lower uptake of $0.9 \pm 0.2 \% \mathrm{ID} / \mathrm{g}$ in BFS-1 tumors for NT experiments (Figure 5E,F). Applying $\mathrm{HT}_{41}$ before injection resulted in a significantly increased ${ }^{111} \mathrm{In}$-TSL accumulation measured after $48 \mathrm{~h}$ in B16 tumors $(5.0 \pm 1.0 \% \mathrm{ID} / \mathrm{g}$; Figure $5 \mathrm{C}, \mathrm{E})$ and BFS-1 tumors $(2.6 \pm 1.0 \% \mathrm{ID} / \mathrm{g}$; Figure 5D, F).

SPECT data were used to fit the liposomal tumor uptake according to a simple two compartment model, deriving the rates for uptake, washout and retention, $k_{\text {in }}, k_{\text {out }}, k_{\text {ret, }}$ in the two different tumors under NT and $\mathrm{HT}_{41}$ conditions (Table 1). Taking the earlier determined pharmacokinetic properties of the

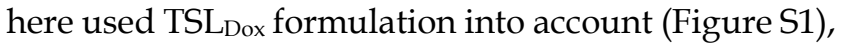
the model also allowed to calculate the concentration of intraliposomal Dox present in the tumors as a function of time (Figure 5C,D). Maximum concentrations of intraliposomal Dox were reached approx. 2 hours p.i.. In contrast to the liposomal concentrations, intraliposomal Dox concentrations decreased to zero 15-20 hours p.i. due to the leakage from the liposomal carrier.

C

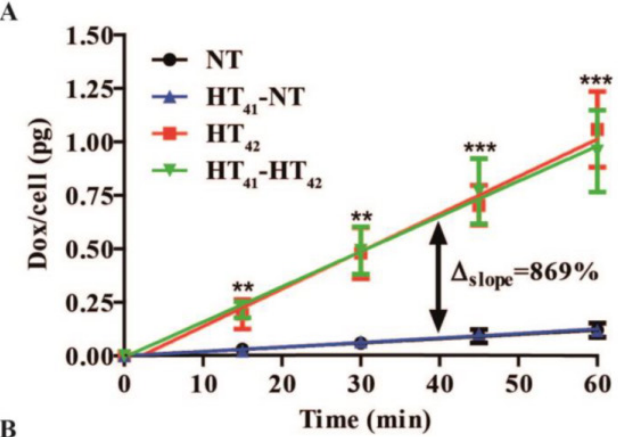

B
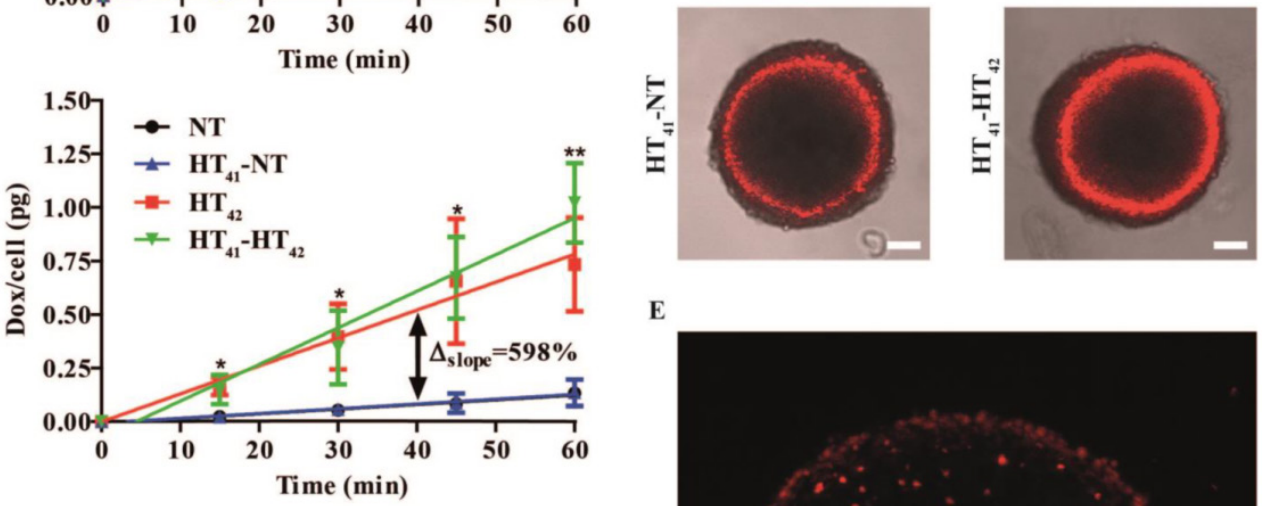

E

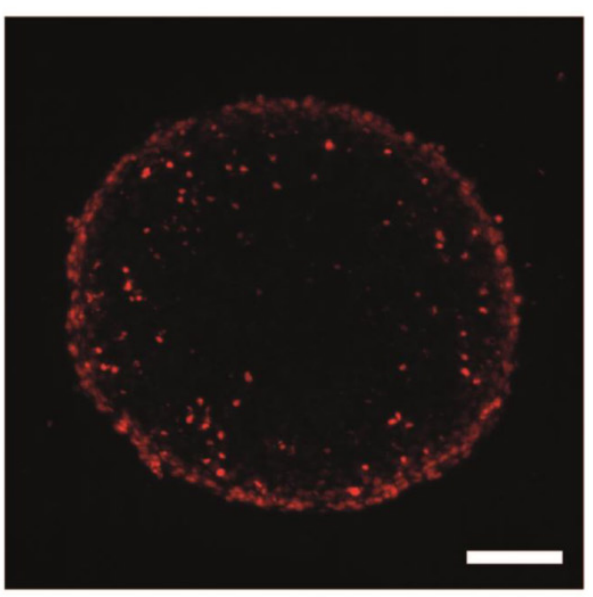

Figure 3. Two-dimensional Dox uptake in B16 (A) and BFS-1 (B) cell cultures and BFS-1 spheroids (C-E). Cells or spheroids were exposed to $40 \mu \mathrm{M}$ Dox for $1 \mathrm{~h}$ at $37{ }^{\circ} \mathrm{C}(\mathrm{NT}), 42^{\circ} \mathrm{C}\left(\mathrm{HT}_{42}\right)$, or preheated at $41^{\circ} \mathrm{C}$ followed by $4 \mathrm{~h}$ at $37^{\circ} \mathrm{C}$ before a $1 \mathrm{~h}$ exposure to $40 \mu \mathrm{M}$ Dox at NT (HT $\left.4 \mathrm{I}-\mathrm{NT}\right)$ or $\mathrm{HT}_{42}\left(\mathrm{HT}_{41}-\mathrm{HT}_{42}\right)$. Optical slices of $5 \mu \mathrm{m}$ made by confocal microscopy of the spheroid (C) were summed up to determine the $\Sigma$ saturated pixels (red) per spheroid (D; Video S1). Cryosections of $10 \mu \mathrm{m}(\mathrm{E})$ of the BFS-1 spheroids show spatial distribution of Dox fluorescence (red). All data sets are composed of an $\mathrm{n}=3$ experiment and compared by one way ANOVA Bonferroni test, $*=p<0.05, * *=p<0.01$, $* * * p<0.005$. Asterisks show significance compared to NT groups. Scale bars represent $100 \mu$ m. 

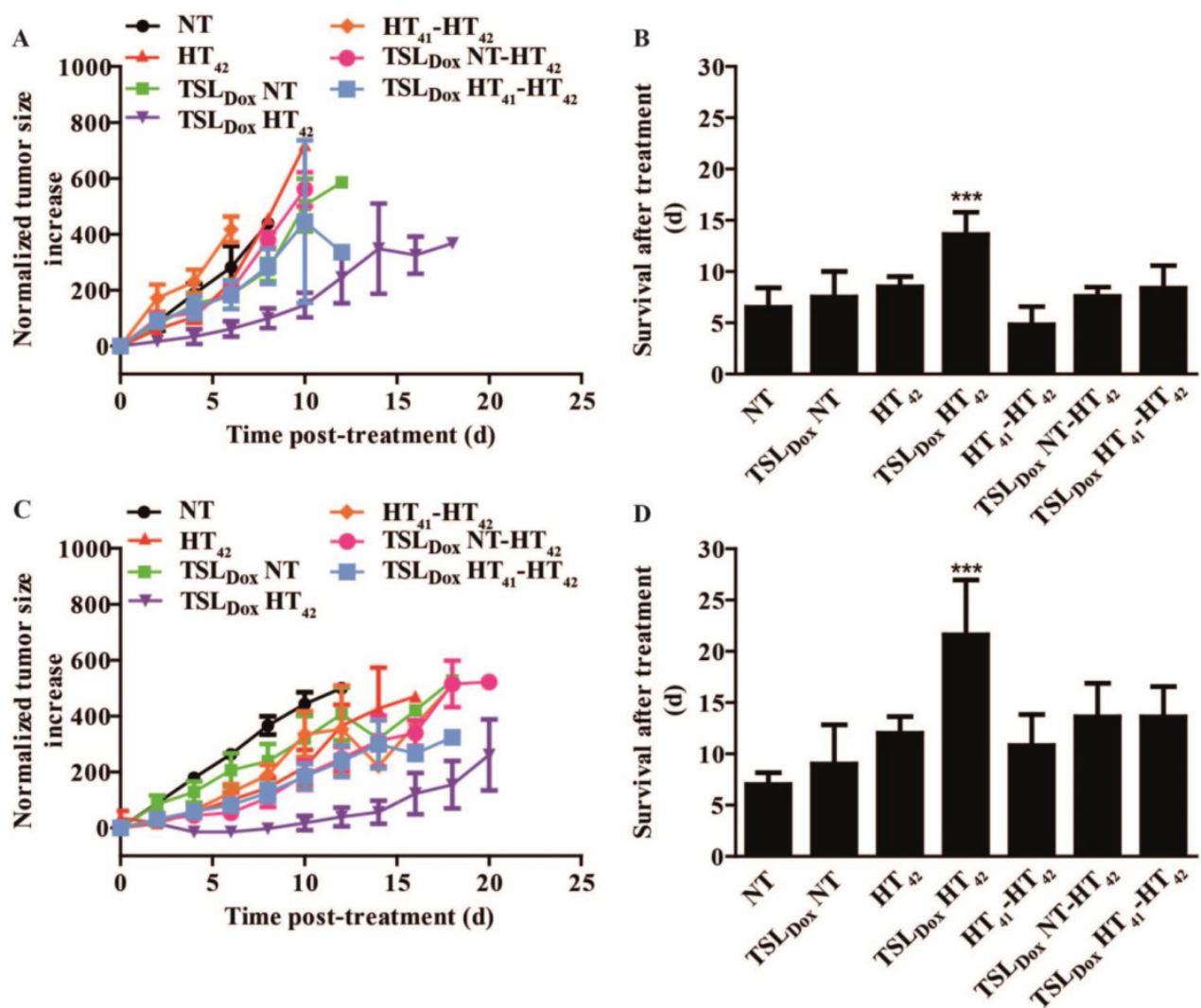

Figure 4. Therapeutic efficacy study in C57BL6 mice with s.c. B16 or BFS-1 tumors. After treatment, results for B16 tumors were plotted for growth (A) and survival (B). Survival (B) was based on a size cutoff at 300\% tumor size increase. Error bars in growth curve (A) represent SEM and one way ANOVA Bonferroni test was used to determine differences of survival in $B(*=p<0.05$, $* *=p<0.01$, **** $=p<0.005)$. Asterisks above bars show significance versus NT. BFS-1 is presented similarly in $C$ and D. $n=4$ for NT, TSLDox NT and HT 42 groups; $n=5$ for all other groups.

The uptake as well as the retention rate of liposomes in B16 tumors was ca. 2 times higher compared to BFS-1 tumors, while washout was comparable for both tumors. Notably, $\mathrm{HT}_{41}$ induced in both tumors a comparable effect with increasing the $k_{i n}$, and $k_{\text {ret }}$ by a factor of ca. $1.66 \pm 0.13$ leading to a more rapid and higher uptake of liposomes and consequently a high Dox peak concentration.

Table 1: Pharmacokinetic parameters describing the tumor TSL uptake and retention in B16 and BFS-1 tumors.

\begin{tabular}{lllll}
\hline Tumor & Condition & $\mathrm{k}_{\text {in }} /(1 / \mathrm{h})$ & $\mathrm{k}_{\text {out }} /(1 / \mathrm{h})$ & $\mathrm{k}_{\text {ret }} /(1 / \mathrm{h})$ \\
\hline B16 & $\mathrm{NT}$ & $0.0157 \pm 0.004$ & $0.39 \pm 0.16$ & $1.4 \pm 0.63$ \\
& $\mathrm{HT}_{41}$ & $0.0233 \pm 0.007$ & $0.36 \pm 0.22$ & $2.5 \pm 1.64$ \\
BFS-1 & $\mathrm{NT}$ & $0.0074 \pm 0.003$ & $0.69 \pm 0.34$ & $0.7 \pm 0.38$ \\
& $\mathrm{HT}_{41}$ & $0.0127 \pm 0.001$ & $0.36 \pm 0.07$ & $1.2 \pm 0.24$ \\
\hline
\end{tabular}

\section{Histology}

After the SPECT-CT study, the tumors were used for H\&E, MSB, TUNEL, CD31 and collagen IV staining (Figure $6 \& 7$ ). H\&E staining indicated that B16 tumors have less strong cellular interactions as can be seen by the gaps in the tissue (Figure 6A), whereas BFS-1 has a much more compact morphology. Furthermore, the H\&E suggests that the B16 tumors are more apoptotic (Figure 6A, arrows). Yet after $\mathrm{HT}_{41}$, apoptotic areas could be seen in both tumor types. MSB staining showed that B16 tumors have a very low presence of extracellular fibers (Figure 6B), whereas BFS-1 showed a more mature extracellular matrix (Figure 6C). Quantitative TUNEL staining (Figure 7A) showed high apoptosis of $14.4 \pm$ $10.0 \%$ for B16 when compared to BFS-1 with $0.4 \pm$ $0.1 \%$. $\mathrm{HT}_{41}$ caused an increase of apoptosis, showing $24.5 \pm 13.2 \%$ for B16 and $1.2 \pm 0.4 \%$ for BFS- 1 , which was a significant increase for the latter. The vessel staining using CD31 indicated a comparable mean vessel density for both tumor models (Figure 7B). The quantitative collagen IV staining confirmed the result of the MSB staining with $3.6 \pm 0.3 \%$ for B16 and $14.8 \pm$ $1.2 \%$ mean density for BFS-1 (Figure 7C). The B16 vessels were relatively large with collagen almost solely associated with the vessels (Figure 7D), whereas BFS-1 vessels were smaller and the interstitium consisted of more extracellular collagen matrix (Figure 7E). 
A

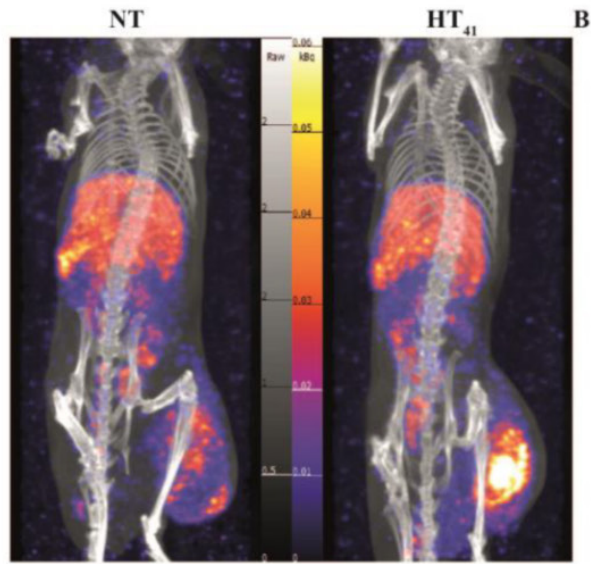

C

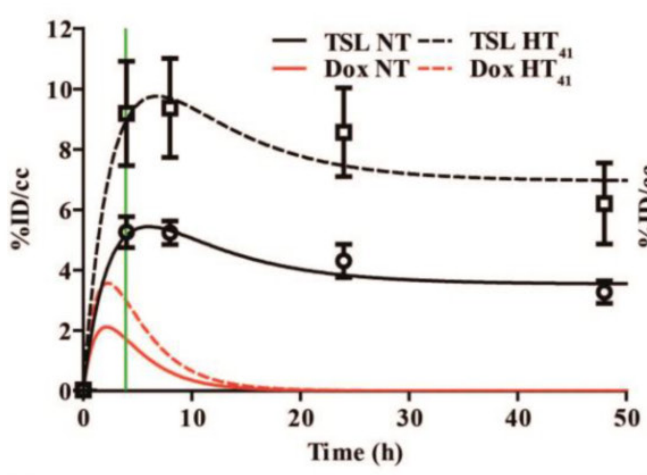

E

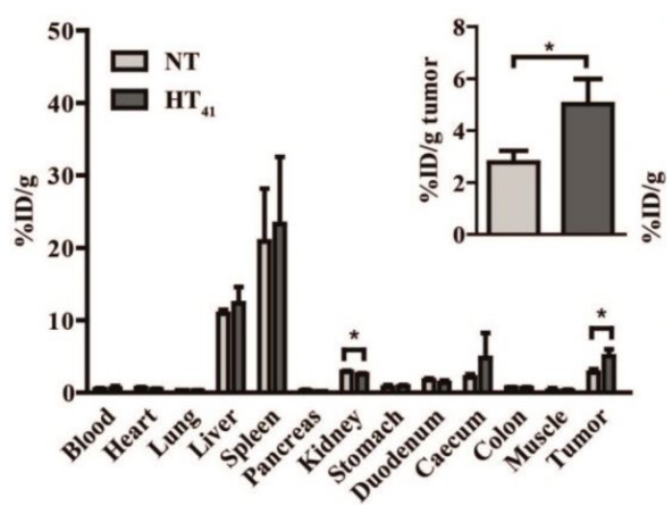

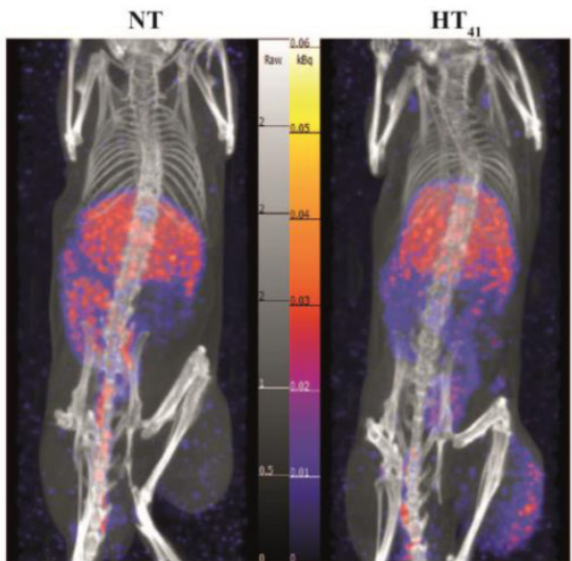

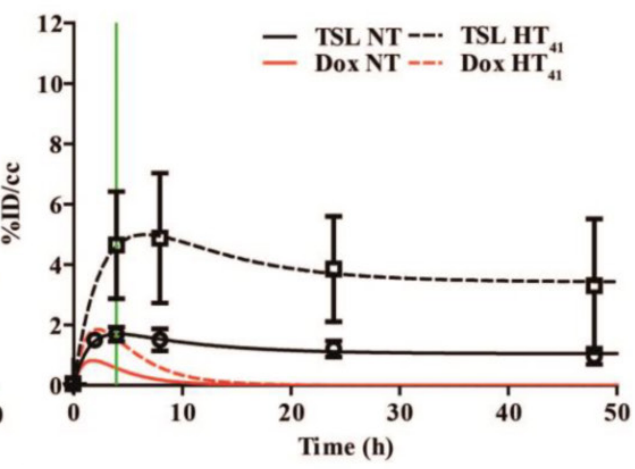

F

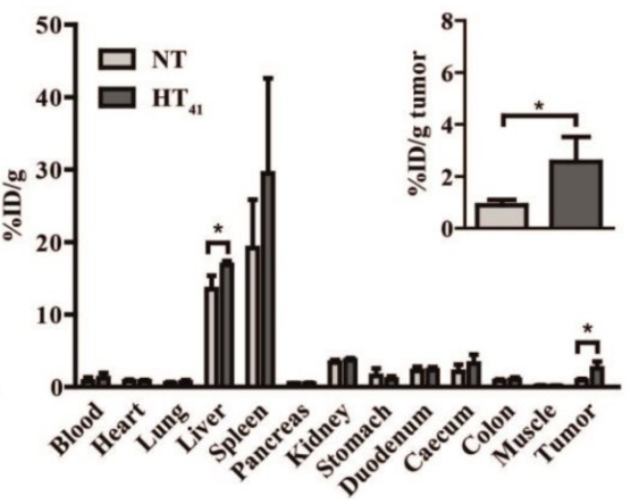

Figure 5. SPECT-CT study on 11 In-TSL distribution in B16 (A, C, E) and BFS-1 (B, D, F) tumor bearing mice. After i.v. administration, scans were made at 4 h, 8 h, $24 \mathrm{~h}$ and $48 \mathrm{~h}$ for all groups. B16 (A, C) and BFS-1 (B,D) tumors showed $11 \mathrm{ln}$-TSL accumulation after i.v. administration at NT, which could be significantly enhanced (unpaired two-tailed t-test; $\mathrm{p}<0.05$ ) by pre-heating the tumor for $1 \mathrm{~h}$ at $41{ }^{\circ} \mathrm{C}$ prior to $111 \mathrm{ln}-\mathrm{TSL}$ administration $(\mathrm{HT} 4 \mathrm{l})$. The green line shows the $4 \mathrm{~h}$ time point where a second HT treatment would have taken place in case of a 2-step therapy. Biodistribution of 11 In-TSL was done by $\mathrm{V}$-counting on excised organs and tumors $(E, F) 48$ hours after injection. Every group consisted of three animals $(n=3)$.

\section{Discussion}

In the field of nanomedicine, substantial research has been performed throughout the last decades on HT-triggered drug release from TSLs for treatment of solid tumors. In this context, mainly 1-step intravascular drug delivery schemes were employed, where tumors are heated to hyperthermic temperatures and drug loaded TSL are injected at the start of the HT treatment. In a previous study conducted by Li et al [36], a 2-step treatment scheme was investigated as a possible alternative in a BLM melanoma xenograft, where first $\mathrm{HT}_{41}$ is applied to enhance vascular permeability, then a TSL Dox formulation was injected that subsequently accumulated in the tumor, followed by a second $\mathrm{HT}_{42}$ step to release the drug from its carrier in order to ensure bioavailability. The aforementioned study showed in contrast to the 1-step therapy, that the 2-step approach was not effective in causing a therapeutic response. In our experimental design we chose for a B16 melanoma and BFS-1 sarcoma cell line because tumors from these cell lines have been previously reported to show high and low 
EPR-mediated uptake of TSL, respectively [31]. We tested how these tumors respond to a 1-step versus 2-step therapy, expanded the knowledge on how the tumor models responded to single versus multiple HT treatments in combination with local chemotherapy and provide extensive information on what factors can cause the differences in TSL accumulation between these tumors and which of these factors could be influenced by HT to increase TSL accumulation.

B16 and BFS-1 cells showed a significant increase in Dox sensitivity when the drug exposure happened during $\mathrm{HT}_{42}$. The reduced $\mathrm{IC}_{50}$ with HT correlated with the increase Dox uptake by the cells discussed hereafter. Previously published data on this correlation showed that the outcome of these experiments depend on cell type and specific

A
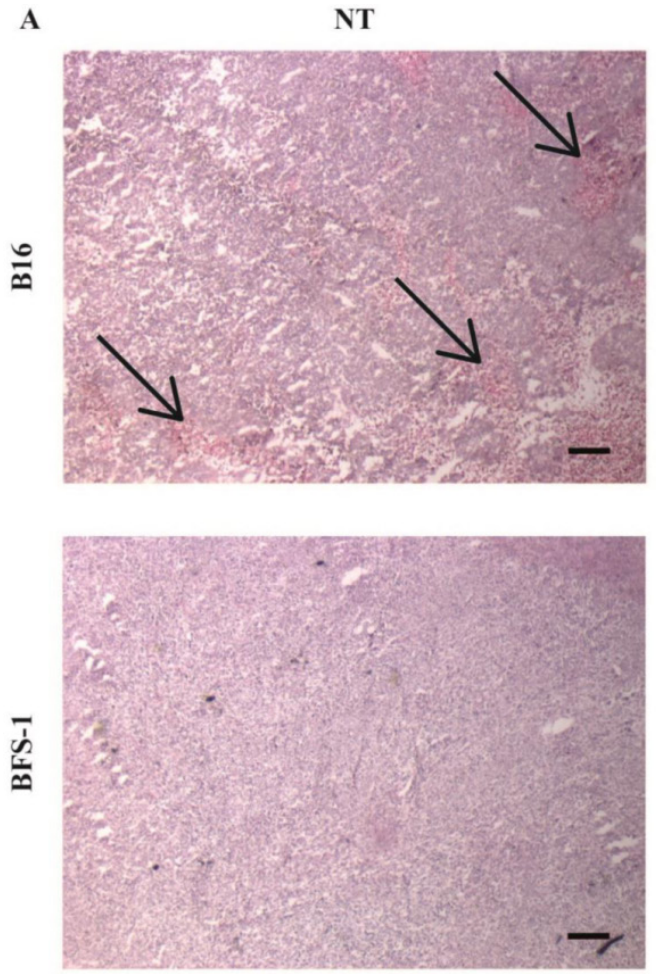

B

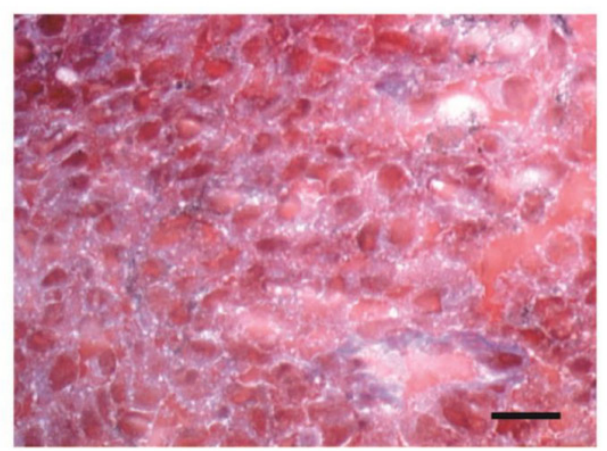

experimental conditions, e.g. exact temperature and duration of HT exposure [27, 41-43]. Testing TSL Dox $_{\text {on }}$ these cells showed that at $37^{\circ} \mathrm{C}$ the cytotoxic effect is minimal, whereas at $42{ }^{\circ} \mathrm{C}$, the $\mathrm{TSL}_{\text {Dox }}$ released all drug and therefore cytotoxicity was comparable to free Dox. The small cytotoxic effect at $37^{\circ} \mathrm{C}$ could be caused by cellular uptake of TSLDox or by Dox leaking from the liposomes into culture medium (Figure S2). Next, we investigated the presence of a synergistic effect of Dox and HT for different heating schemes in a 2D and 3D cellular model. In a 2D model, it was shown that $\mathrm{HT}_{42}$ induces a faster cellular uptake of Dox leading to a 6-9 times higher rate of uptake in B16 and BFS-1 cells than at $37^{\circ} \mathrm{C}$. Preheating the cells for 1 $\mathrm{h}$ with $\mathrm{HT}_{41}$ followed by incubation for $4 \mathrm{~h}$ at $37^{\circ} \mathrm{C}$ before adding Dox did not show any improvement of Dox uptake, indicating that HT-induced effects at 41
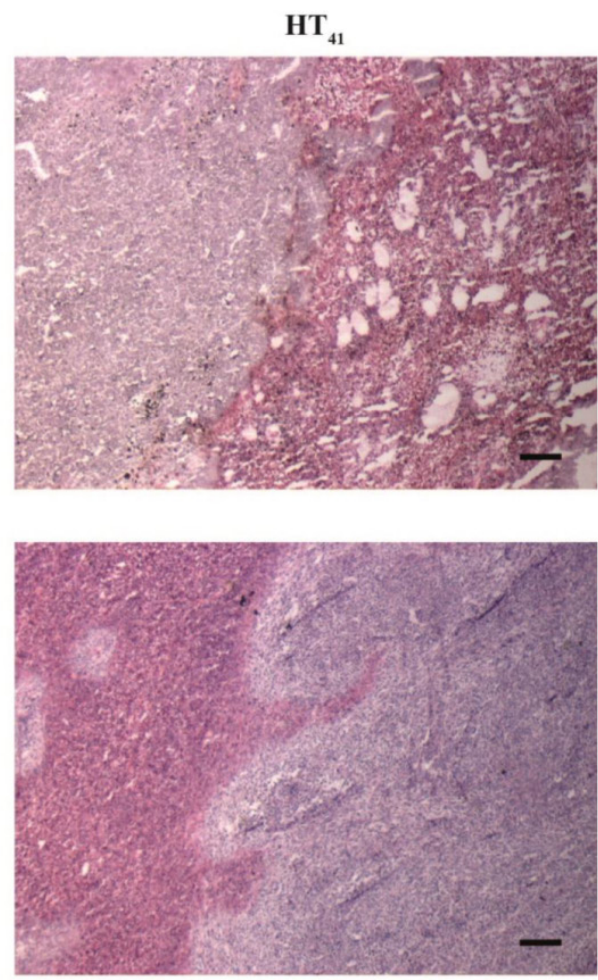

C

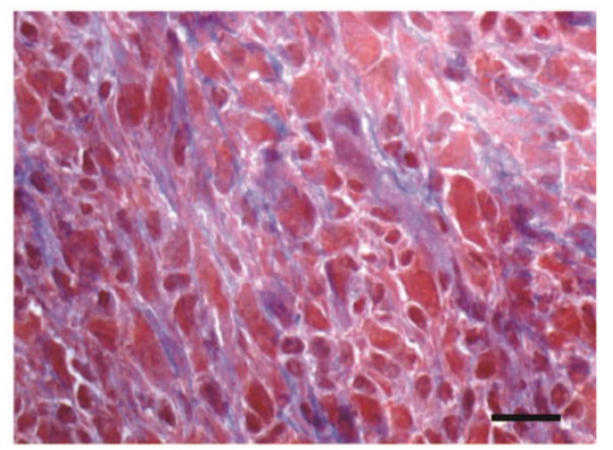

Figure 6. $5 \mu \mathrm{m}$ H\&E stained sections of B16 and BFS-1 tumors $48 \mathrm{~h}$ after NT or $\mathrm{HT}_{41}$ (A). Black arrows indicate apoptotic areas. MSB stained B16 (B) and BFS-1 (C) with collagen stained in blue. Scale bars represent $200 \mu \mathrm{m}$ in $\mathrm{A}$ and $20 \mu \mathrm{m}$ in B and $\mathrm{C}$. 
${ }^{\circ} \mathrm{C}$ were reversible in nature and could only improve drug uptake during the heating and not thereafter. As the Dox uptake is caused by passive diffusion across the cell membrane, increase of cellular membrane fluidity and permeability during HT is the most likely explanation, since these effects are temporal in nature and fully reversible [27, 28]. Other studies have shown that preheating to slightly higher temperatures of $43-45.5^{\circ} \mathrm{C}$ lead to a reduced Dox uptake most likely due to a more permanent and irreversible temperature of thermal dose induced damage [41, 44]. However, $\mathrm{HT}_{41}$ used for preheating in this study did not induce this effect as has also been reported by others [45]. Spheroids mimic a solid tumor in terms of cell physiology, presence of extracellular matrix and an apoptotic core [46]. For this reason, we employed this model to investigate whether Dox penetration depth into a dense structure of cells is influenced by different heating conditions $[47,48]$. BFS- 1 spheroids showed a similar response in Dox uptake as the 2D model when different HT protocols were applied. However, it also showed that if cells are closely packed, the drug does not penetrate deep into the structure beyond the first few layers of cells. Neither the spatial distribution nor the penetration depth could be improved by HT in tumor spheroids. A comparative study using B16 cells was not possible since B16 cells did not form spheroids. The latter might be caused by the lack of a substantial cell-cell adherence, which was also observed in ex vivo examination of B16 tumors described later in this section.

At this stage we have only shown the potential of local chemotherapy and HT in vitro. However, the described features are only a small part of the factors that have to be considered for drug delivery to solid tumors. Therefore, we performed a therapeutic study as well as in vivo imaging and extensive ex vivo investigation on B16 and BFS-1 tumors to better understand the factors that could have played a role in various therapeutic responses. For both tumor types, a 1-step approach where TSLDox is i.v. administered during $\mathrm{HT}_{42}$ gave a significant therapeutic response, whereas a 2-step approach which relied on TSL ${ }_{\text {Dox }}$ accumulation in a preheated $\left(\mathrm{HT}_{41}\right)$ tumor followed by a second $\mathrm{HT}_{42}$ step to induce drug release did not show a therapeutic effect. The SPECT/CT imaging in this case was particularly valuable to follow the TSL accumulation in B16 and BFS-1 tumors. The SPECT data were used for fitting a two compartment model which describes tumor uptake of the liposomal carrier as well as the intraliposomal Dox concentration in the tumor taking the blood kinetic and pharmacokinetic parameters of
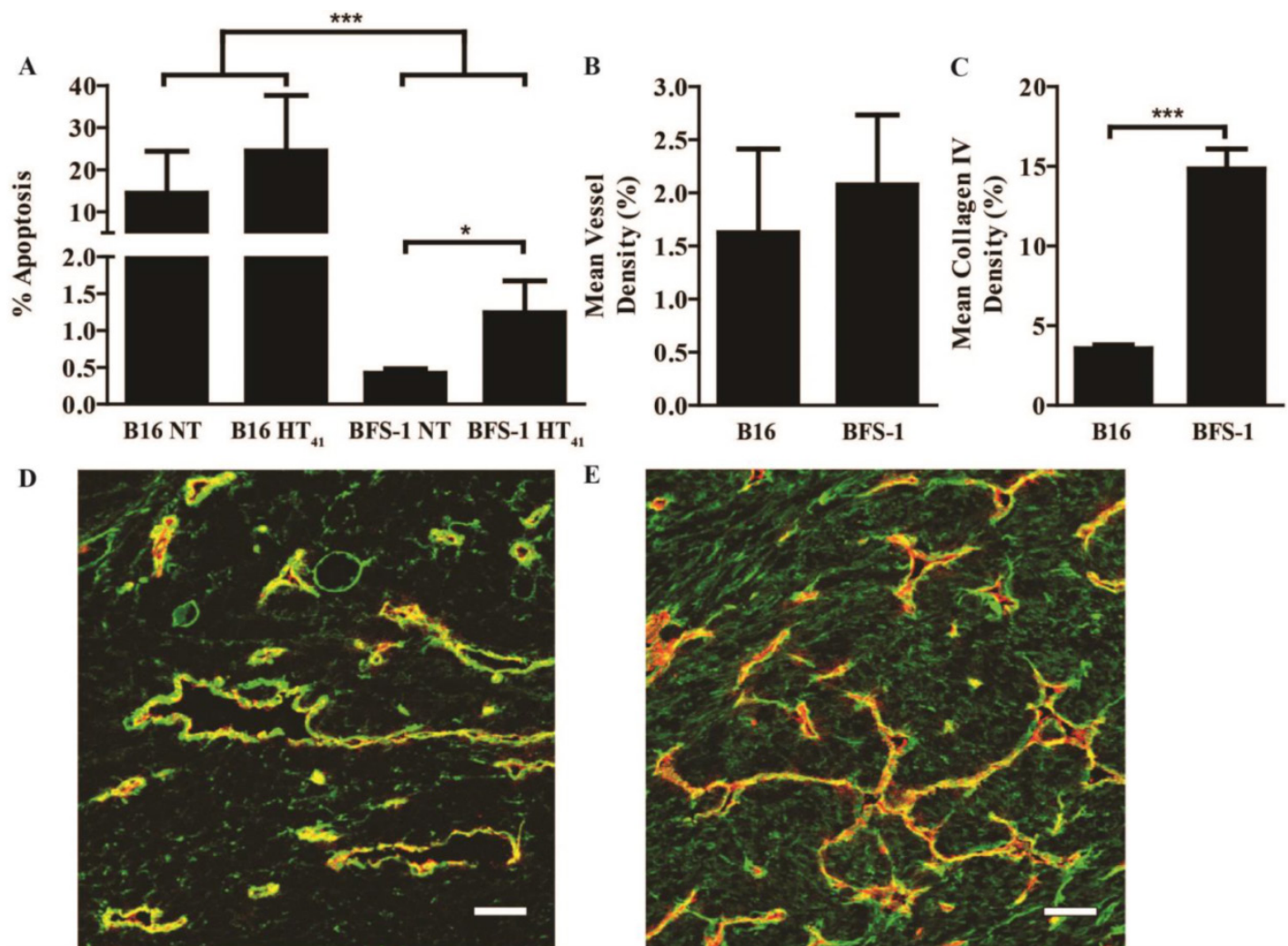

Figure 7. Quantification of cryo-section staining with TUNEL (A), CD31 (B) and collagen IV (C) was analyzed by unpaired two tailed t-test $(*=p<0.05)$. B16 (D) and BFS-1 (E) blood vessels colored red for CD31. Collagen IV stained in green. Scale bar shows $50 \mu \mathrm{m}$. $\mathrm{n}=3$ for all groups. 
TSLDox into account [39]. For both tumors and regardless of applying $\mathrm{HT}_{41}$ beforehand, the maximum concentration of liposomes was reached approx. $4 \mathrm{~h}$ p.i., when the second $\mathrm{HT}_{42}$ step was applied. The B16 tumors showed a significantly higher liposomal uptake compared to the BFS-1 tumor with ca. two fold higher $k_{i n}$ and $k_{\text {ret }}$ parameters reflecting a higher intrinsic EPR effect for the B16 model. Interestingly, 1 hour of $\mathrm{HT}_{41}$ induced the same effect in both tumors leading to a 1.66 times increase in $k_{i n}$ and $k_{r e t}$ and thus maintaining the two fold higher uptake of TSLs in B16 compared to BFS1 tumors.

However, calculations suggested that maximum intraliposomal Dox concentrations were already reached $2 \mathrm{~h}$ p.i., and declining to zero within $20 \mathrm{~h}$ due to leakage from the TSLs. These data imply that a more favorable time point for the second $\mathrm{HT}_{42}$ step is ca. 2-3 h p.i. [36]. Based on our calculations, the intraliposomal Dox reached concentrations of $1.7 \%$ ID/cc for B16 and $0.6 \%$ ID/cc Dox for BFS-1 at the moment of the second $\mathrm{HT}_{42}$ step (i.e. after $4 \mathrm{~h}$ ) at normal temperature conditions, and $3.0 \% \mathrm{ID} / \mathrm{cc}$ and $1.5 \%$ ID/cc Dox with a preceding $\mathrm{HT}_{41}$ treatment. These concentrations are lower compared to typical values found for a 1-step delivery approach [49], which provides an explanation for the lack of a significant therapeutic response in a 2-step drug delivery protocol.

Finally, we performed histological analysis of excised tumors and investigated factors that may cause the differences in TSL uptake and the intrinsically higher EPR effect found in B16 and BFS-1 tumors. B16 tumors grew more aggressively than BFS-1, reaching volumes of $200 \mathrm{~mm}^{3}$ in 7-14 and 14-21 days after inoculation, respectively. Especially in preclinical models, fast growing tumors show higher structural and functional abnormalities of the vasculature, thereby increasing the odds for a high EPR effect $[1,50,51]$. The mean vessel density was similar for B16 and BFS-1, however the morphology of B16 vessels appeared more tortuous and overall larger in size. Next to the growth rate and vascular properties, we also observed noticeable differences in cell packing and organization, which is important for the penetration depth of extravasated compounds into the tumor interstitium $[47,52,53]$. H\&E staining showed less dense cellular packing with gaps in the B16 tumor tissue, whereas BFS-1 showed a higher density and no gaps. Therefore, the finding that BFS-1 cells could form spheroids while B16 cells did not, might be indicative for cell packing and organization in an actual tumor. In vivo, cell packing density and organization is, among other reasons, depends on the presence of a well-defined extracellular matrix. Analysis on the extracellular matrix by MSB staining and quantitative collagen IV immunostaining showed that B16 tumors have an almost completely absent extracellular matrix, whereas BFS-1 tumors had a more mature extracellular matrix. These findings suggest that the immature interstitium of the B16 tumor could have played a role in facilitating a higher EPR, confirming previously published results [54]. Histological analysis and quantitative TUNEL staining also indicated a much higher amount of apoptosis in the B16 tumors than in the BFS-1 tumors, which is typically associated with a more pronounced EPR effect [55, 56]. The $\mathrm{HT}_{41}$ induced increase of apoptosis was significant for the sectioned BFS-1 tumors. While our study is in line with earlier findings showing that HT increases vascular permeability and promotes extravasation of nanoparticles [29-31], our histology data also suggest that substantial $\mathrm{HT}_{41}$ induced apoptosis can further aid EPR.

In summary, we have shown that HT can aid in drug delivery by making cells more susceptible for Dox uptake, increasing the EPR-mediated uptake of liposomal drugs and by providing a trigger for drug release from TSL $L_{\text {Dox. }}$ All above factors play a pivotal role in the here employed 2-step delivery scheme. However, the actual amount of Dox delivered in a 2-step approach is determined by liposomal uptake and stability of the formulation and can therefore never exceed the liposomal uptake (in \%ID/g). This study has shown that preheated B16 and BFS-1 tumors accumulated a maximum of $9.8 \% \mathrm{ID} / \mathrm{cc}$ and $5.0 \% \mathrm{ID} / \mathrm{cc}$ of the injected TSL dose, while the intraliposomal Dox concentration only reached 3 and $1.5 \%$ ID/cc at 4 hours p.i. respectively. These Dox concentrations appeared insufficient to induce a noticeable therapeutic response. The 1-step intravascular drug release seems to be advantageous, since the injected $\mathrm{TSL}_{\text {Dox }}$ provide a high plasma concentration of Dox exposing the tumor to a high area under the curve over the time span of HT. Furthermore, the HT induced increase in Dox uptake by tumor cells may lead in both delivery schemes to a higher intracellular concentration.

\section{Supplementary Material}

Additional File 1:

Figure S1-S4. http:/ / www.thno.org/v06p1717s1.pdf Additional File 2:

Video S1. http:/ / www.thno.org/v06p1717s2.mp4

\section{Abbreviations}

TSL: thermosensitive liposome; HT: hyperthermia; NT: normothermia; Dox: Doxorubicin; EPR: enhanced permeability and retention. 


\section{Acknowledgements}

We would like to acknowledge NanoNextNL Project 03D.02 for funding. Furthermore, we would like to thank Erik de Blois, Stuart Koelewijn and Jan de Swart from the departments of Nuclear Medicine and Radiology of the Erasmus MC for technical support on radiolabeling of TSL and SPECT-CT experiments. We thank Gert van Cappellen from the Optical Imaging Center, Erasmus MC, for advice on quantification of fluorescence microscopy data.

\section{Competing interests}

The authors have declared that no competing interest exists.

\section{References}

1. Jain RK. Normalization of Tumor Vasculature: An Emerging Concept in Antiangiogenic Therapy. Science. 2005; 307: 58-62.

2. Nagy JA, Chang SH, Dvorak AM, Dvorak HF. Why are tumour blood vessels abnormal and why is it important to know? Br J Cancer. 2009; 100: 865-9.

3. Hobbs SK, Monsky WL, Yuan F, Roberts WG, Griffith L, Torchilin VP, et al. Regulation of transport pathways in tumor vessels: role of tumor type and microenvironment. Proc Natl Acad Sci US A. 1998; 95: 4607-12.

4. Hashizume H, Baluk P, Morikawa S, McLean JW, Thurston G, Roberge S, et al. Openings between defective endothelial cells explain tumor vessel leakiness. Am J Pathol. 2000; 156: 1363-80.

5. Kobayashi H, Watanabe R, Choyke PL. Improving conventional enhanced permeability and retention (EPR) effects; what is the appropriate target? Theranostics. 2013; 4: 81-9.

6. Allen TM, Cullis PR. Drug delivery systems: entering the mainstream. Science. 2004; 303: 1818-22.

7. Allen TM, Cullis PR. Liposomal drug delivery systems: from concept to clinical applications. Adv Drug Deliv Rev. 2013; 65: 36-48.

8. Matsumura Y, Maeda H. A new concept for macromolecular therapeutics in cancer chemotherapy: mechanism of tumoritropic accumulation of proteins and the antitumor agent smancs. Cancer Res. 1986; 46: 6387-92.

9. Gabizon A, Catane R, Uziely B, Kaufman B, Safra T, Cohen R, et al. Prolonged circulation time and enhanced accumulation in malignant exudates of doxorubicin encapsulated in polyethylene-glycol coated liposomes. Cancer Res. 1994; 54: 987-92.

10. Gabizon A, Shmeeda H, Barenholz Y. Pharmacokinetics of pegylated liposomal doxorubicin - Review of animal and human studies. Clin Pharmacokinet. 2003; 42: 419-36.

11. Laginha KM, Verwoert S, Charrois GJR, Allen TM. Determination of doxorubicin levels in whole tumor and tumor nuclei in murine breast cancer tumors. Clinical Cancer Research. 2005; 11: 6944-9.

12. Yatvin MB, Weinstein JN, Dennis WH, Blumenthal R. Design of liposomes for enhanced local release of drugs by hyperthermia. Science. 1978; 202: 1290-3.

13. Needham D, Anyarambhatla G, Kong G, Dewhirst MW. A new temperature-sensitive liposome for use with mild hyperthermia: characterization and testing in a human tumor xenograft model. Cancer Res. 2000; 60: 1197-201.

14. Li L, ten Hagen TL, Hossann M, Suss R, van Rhoon GC, Eggermont AM, et al. Mild hyperthermia triggered doxorubicin release from optimized stealth thermosensitive liposomes improves intratumoral drug delivery and efficacy. J Control Release. 2013; 168: 142-50.

15. de Smet $M$, Langereis $S$, van den Bosch $S$, Grull $H$. Temperature-sensitive liposomes for doxorubicin delivery under MRI guidance. J Control Release. 2010; $143:$ 120-7.

16. Lindner $\mathrm{LH}$, Eichhorn ME, Eibl H, Teichert N, Schmitt-Sody M, Issels RD, et al Novel temperature-sensitive liposomes with prolonged circulation time. Clin Cancer Res. 2004; 10: 2168-78.

17. de Smet M, Heijman E, Langereis S, Hijnen NM, Grull H. Magnetic resonance imaging of high intensity focused ultrasound mediated drug delivery from temperature-sensitive liposomes: an in vivo proof-of-concept study. J Control Release. 2011; 150: 102-10.

18. Celsion. Phase 3 Study of ThermoDox With Radiofrequency Ablation (RFA) in Treatment of Hepatocellular Carcinoma (HCC). ClinicalTrialsgov NCT00617981; 2008

19. Celsion. Study of ThermoDox With Standardized Radiofrequency Ablation (RFA) for treatment of Hepatocellular Carcinoma (HCC) (OPTIMA). ClinicalTrialsgov NCT02112656; 2014

20. Overgaart J. Effect of hyperthermia on malignant cells in vivo: A review and a hypothesis. Cancer. 1977; 39: 2637-46.
21. Song CW. Effect of Local Hyperthermia on Blood-Flow and Microenvironment - a Review. Cancer Research. 1984; 44: 4721-30.

22. Calabro A, Singletary SE, Tucker S, Boddie A, Spitzer G, Cavaliere R. In vitro thermo-chemosensitivity screening of spontaneous human tumors: significant potentiation for cisplatin but not adriamycin. Int J Cancer. 1989; 43: 385-90.

23. Sakaguchi Y, Stephens LC, Makino M, Kaneko T, Strebel FR, Danhauser LL, et al. Apoptosis in tumors and normal tissues induced by whole body hyperthermia in rats. Cancer Res. 1995; 55: 5459-64.

24. Yarmolenko PS, Moon EJ, Landon C, Manzoor A, Hochman DW, Viglianti BL, et al. Thresholds for thermal damage to normal tissues: an update. Int J Hyperthermia. 2011; 27: 320-43.

25. Hildebrandt B, Wust P, Ahlers O, Dieing A, Sreenivasa G, Kerner T, et al. The cellular and molecular basis of hyperthermia. Crit Rev Oncol Hematol. 2002; 43: 33-56.

26. Issels RD, Lindner $\mathrm{LH}$, Verweij J, Wust $\mathrm{P}$, Reichardt $\mathrm{P}$, Schem $\mathrm{BC}$, et al. Neo-adjuvant chemotherapy alone or with regional hyperthermia for localised high-risk soft-tissue sarcoma: a randomised phase 3 multicentre study. Lancet Oncol. 2010; 11: 561-70.

27. Bates DA, Mackillop WJ. Hyperthermia, adriamycin transport, and cytotoxicity in drug-sensitive and -resistant Chinese hamster ovary cells. Cancer Res. 1986; 46: 5477-81.

28. Kawai H, Minamiya Y, Kitamura M, Matsuzaki I, Hashimoto M, Suzuki H, et al. Direct measurement of doxorubicin concentration in the intact, living single cancer cell during hyperthermia. Cancer. 1997; 79: 214-9.

29. Huang SK, Stauffer PR, Hong K, Guo JW, Phillips TL, Huang A, et al. Liposomes and hyperthermia in mice: increased tumor uptake and therapeutic efficacy of doxorubicin in sterically stabilized liposomes. Cancer Res. 1994; 54: 2186-91.

30. Kong G, Braun RD, Dewhirst MW. Characterization of the effect of hyperthermia on nanoparticle extravasation from tumor vasculature. Cancer Res. 2001; 61: 3027-32.

31. Li L, ten Hagen TLM, Bolkestein M, Gasselhuber A, Yatvin J, van Rhoon GC, et al. Improved intratumoral nanoparticle extravasation and penetration by mild hyperthermia. Journal of Controlled Release. 2013; 167: 130-7.

32. de Smet M, Langereis $S$, van den Bosch $S$, Bitter $K$, Hijnen NM, Heijman E, et al. SPECT/CT imaging of temperature-sensitive liposomes for MR-image guided drug delivery with high intensity focused ultrasound. J Control Release. 2013; 169: 82-90.

33. Matteucci ML, Anyarambhatla G, Rosner G, Azuma C, Fisher PE, Dewhirst MW, et al. Hyperthermia increases accumulation of technetium-99m-labeled liposomes in feline sarcomas. Clin Cancer Res. 2000; 6: 3748-55.

34. Alvarez Secord A, Jones EL, Hahn CA, Petros WP, Yu D, Havrilesky LJ, et al. Phase I/II trial of intravenous Doxil and whole abdomen hyperthermia in patients with refractory ovarian cancer. Int J Hyperthermia. 2005; 21: 333-47.

35. Vujaskovic Z, Kim DW, Jones E, Lan L, McCall L, Dewhirst MW, et al. A phase I/II study of neoadjuvant liposomal doxorubicin, paclitaxel, and hyperthermia in locally advanced breast cancer. Int J Hyperthermia. 2010; 26: 514-21.

36. Li L, ten Hagen TL, Haeri A, Soullie T, Scholten C, Seynhaeve AL, et al. A novel two-step mild hyperthermia for advanced liposomal chemotherapy. J Control Release. 2014; 174: 202-8.

37. Bartlett GR. Phosphorus Assay in Column Chromotography. Journal of Biological Chemistry. 1959; 234: 466-8.

38. Nagelkerke A, Bussink J, Sweep FC, Span PN. Generation of multicellular tumor spheroids of breast cancer cells: how to go three-dimensional. Anal Biochem. 2013; 437: 17-9.

39. Lokerse WJM, Kneepkens ECM, ten Hagen TLM, Eggermont AMM, Grüll H, Koning GA. In depth study on thermosensitive liposomes: Optimizing formulations for tumor specific therapy and in vitro to in vivo relations. Biomaterials. 2016; http://dx.doi.org/10.1016/j.biomaterials.2015.12.023.

40. Eddy HA. Alterations in tumor microvasculature during hyperthermia. Radiology. 1980; 137: 515-21.

41. Hahn GM, Strande DP. Cytotoxic effects of hyperthermia and adriamycin on Chinese hamster cells. J Natl Cancer Inst. 1976; 57: 1063-7.

42. Herman TS. Temperature dependence of adriamycin, cis-diamminedichloroplatinum, bleomycin, and 1,3-bis(2-chloroethyl)-1-nitrosourea cytotoxicity in vitro. Cancer Res. 1983; 43: $517-20$.

43. Nagaoka S, Kawasaki S, Sasaki K, Nakanishi T. Intracellular uptake, retention and cytotoxic effect of adriamycin combined with hyperthermia in vitro. Jpn J Cancer Res. 1986; 77: 205-11.

44. Rice GC, Hahn GM. Modulation of adriamycin transport by hyperthermia as measured by fluorescence-activated cell sorting. Cancer Chemother Pharmacol. 1987; 20: 183-7

45. Moriyama-Gonda N, Igawa M, Shiina $\mathrm{H}$, Wada $\mathrm{Y}$. Heat-induced membrane damage combined with adriamycin on prostate carcinoma PC-3 cells: correlation of cytotoxicity, permeability and P-glycoprotein or metallothionein expression. Br J Urol. 1998; 82: 552-9.

46. Hirschhaeuser $\mathrm{F}$, Menne $\mathrm{H}$, Dittfeld $\mathrm{C}$ West $\mathrm{J}$ Mueller-Klieser W, Kunz-Schughart LA. Multicellular tumor spheroids: an underestimated tool is catching up again. J Biotechnol. 2010; 148: 3-15.

47. Mikhail AS, Eetezadi S, Ekdawi SN, Stewart J, Allen C. Image-based analysis of the size- and time-dependent penetration of polymeric micelles in multicellular tumor spheroids and tumor xenografts. Int J Pharm. 2014; 464: $168-77$. 
48. Kim TH, Mount CW, Gombotz WR, Pun SH. The delivery of doxorubicin to 3-D multicellular spheroids and tumors in a murine xenograft model using tumor-penetrating triblock polymeric micelles. Biomaterials. 2010; 31: 7386-97.

49. Hijnen N, Langereis S, Grull H. Magnetic resonance guided high-intensity focused ultrasound for image-guided temperature-induced drug delivery. Advanced Drug Delivery Reviews. 2014; 72: 65-81.

50. Dvorak HF, Nagy JA, Dvorak JT, Dvorak AM. Identification and characterization of the blood vessels of solid tumors that are leaky to circulating macromolecules. Am J Pathol. 1988; 133: 95-109.

51. Lammers T, Kiessling F, Hennink WE, Storm G. Drug targeting to tumors: principles, pitfalls and (pre-) clinical progress. J Control Release. 2012; 161: $175-87$.

52. McGuire S, Yuan F. Improving interstitial transport of macromolecules through reduction in cell volume fraction in tumor tissues. Nanomedicine. 2012; 8: 1088-95.

53. Minchinton AI, Tannock IF. Drug penetration in solid tumours. Nat Rev Cancer. 2006; 6: 583-92.

54. Netti PA, Berk DA, Swartz MA, Grodzinsky AJ, Jain RK. Role of extracellular matrix assembly in interstitial transport in solid tumors. Cancer Res. 2000; 60: 2497-503.

55. Jang SH, Wienties MG, Au JL. Enhancement of paclitaxel delivery to solid tumors by apoptosis-inducing pretreatment: effect of treatment schedule. J Pharmacol Exp Ther. 2001; 296: 1035-42.

56. Heneweer C, Holland JP, Divilov V, Carlin S, Lewis JS. Magnitude of Enhanced Permeability and Retention Effect in Tumors with Different Phenotypes: Zr-89-Albumin as a Model System. J Nucl Med. 2011; 52: 625-33. 